\title{
Original article \\ Antibiotic resistance pattern of bacteria causing urinary tract infection in a private medical college hospital, Dhaka \\ Siddiqua $M^{1}$, Alam $A N^{2}$, Akter $S^{3}$, Ferdousi $R S^{4}$
}

\begin{abstract}
:
Background and objective: Urinary tract infection (UTI) is one of the frequently seen infections both in the world and in our country as well. Escherichia coli (E. coli) aremost frequently isolated in complicated or uncomplicated, nosocomial or community acquired urinary tract infections. To guide the empirical therapy, the resistance pattern of $E$. coli responsible was evaluated throughout the period in this study. Material and Method: Urine samples from outpatient / inpatient department of Ibn Sina Medical College Hospital between $1^{\text {st }}$ January, 2015 and $31^{\text {st }}$ December, 2015 were retrospectively analyzed. Presence of $\geq 10^{5}$ colony forming units $/ \mathrm{ml}$ in urine culture was considered as significant for UTI. Isolated bacteria were identified by standard laboratory techniques and antibiotic susceptibility testing was performed by Kirby-Bauer disk diffusion method using Clinical Laboratory Standard Institute (CLSI) criteria. Result: A total of 271(13.4\%) uropathogens were isolated. Overall E. coli accounted for $180(66.42 \%)$ of all isolates. Resistance rates of $E$. coli to antimicrobial agents was demonstrated to be as follows: cefuroxime $82 \%$, nalidaxic acid $74 \%$, azithromycin $56 \%$, cefotaxime $52 \%$, ceftazidime $50 \%$, cefixime $47 \%$, cotrimoxazole $43 \%$, ceftriaxone $41 \%$, ciprofloxacin $38 \%$, amoxicillin-clavulanic acid $31 \%$, cefepime $30 \%$, and low resistance which ranges from 9 to $1 \%$ included gentamycin $9 \%$, meropenem 3\%, imipenem $2 \%$, nitrofurantoin $2 \%$ and amikacin 1\%. Conclusion: As resistance rates show regional differences, it is necessary to regularly monitor regional resistance pattern to determine the appropriate empiric antibiotic treatment. The national antibiotic usage policies must be reorganized according to data obtained from these studies.
\end{abstract}

$\underline{\text { Keywords: }}$ Urinary tract infection (UTI); Antibiotic resistance pattern; Escherichia coli (E. coli)

Bangladesh Journal of Medical Science Vol. 16 No. 01 January'17. Page : 42-47

\section{Introduction:}

Urinary tract infections (UTIs) are a major cause of morbidity world wide and second most common infectious disease in community. Approximately 150 million cases are diagnosed each year ${ }^{1}$. It is estimated that about $35 \%$ of healthy women suffer from symptoms of urinary tract infection at some point in their life. The incidence of UTI is greater in women as compared to men, which may be either due to anatomical predisposition or other host factors ${ }^{2}$.
Vaginal colonization with uropathogens precedes most UTIs and also sexual activity, pregnancy, obstruction are among the other factors contributing to increasing frequency of UTI in female ${ }^{3}$.

UTI is commonly caused by Escherichia coli, Proteus, Klebsiella, Enterococcus, and Enterobacter $\mathrm{spp}^{4}$. Most frequently Escherichia coli are isolated in complicated or uncomplicated, nosocomial or community acquired urinary tract infections ${ }^{5,6,7}$. Antimicrobial resistance among

1. Dr. Mahmuda Siddiqua, Associate Professor, Department of Microbiology, Ibn Sina Medical College, Dhaka.

2. Dr. Ahmed Nawsher Alam, Principal Scientific Officer, Institute of Epidemiology Disease Control and Research, Dhaka.

3. Dr. Sonia Akter, Assistant Professor, Department of Microbiology, Ibn Sina Medical College, Dhaka.

4. Professor Reena Saad Ferdousi, Head, Department of Microbiology, Ibn Sina Medical College, Dhaka.

Correspondence to: Dr. Mahmuda Siddiqua, Associate Professor, Department of Microbiology, Ibn Sina Medical College, Dhaka. E-mail: mahmuda99@yahoo.com 
uropathogenic E. coli may be increased with temporal and geographic fluctuations which may introduce multidrug resistant $E$. coli into the community ${ }^{8}$. It has been recommended that guiding data adjusted to epidemiological data should be used in the selection of routine treatment ${ }^{5,9}$. Therefore regionspecific microorganisms and their antimicrobial susceptibilities should be determined.

Indiscriminate use of antimicrobial agents is a common practice in underdeveloped and many developing countries that often leads to emergence of resistant microorganisms. So, the scope for effective antibiotic to combat bacterial infections including UTI sgradually decreased ${ }^{10}$.As a common practice, empirical antimicrobial treatment is initiated before the laboratory results of urine culture are available which may lead to emergence and spread of antimicrobial resistant strains. Factually, antimicrobial resistance is one of the principal causes of treatment failure in infectious diseases and a great concern for UTIs ${ }^{11}$. The prevalence and pattern of antimicrobial resistance of uropathogens are dependent on many factors. Continuous monitoring of resistance pattern is of paramount importance for not only selecting appropriate drugs but also for rational choice of empirical therapy ${ }^{12}$.

The present investigation was carried out to determine the recent status of prevalence of bacterial pathogens and their antimicrobial resistance in UTI patients. The aim of this study is to guide physicians to provide information about choice of proper antibiotic for empirical treatment.

\section{Material and methods:}

A study was carried out in the Microbiology department of Ibn Sina Medical College Hospital from January 2015 to December 2015. Urine samples were collected from outpatient and inpatient department for routine microscopic examination and culture sensitivity. Culture plates were incubated at a mean ambient temperature of $35 \pm 2^{\circ} \mathrm{C}$ for 18 48 hours; bacterial growths of $\geq 10^{5} \mathrm{CFU} / \mathrm{ml}$ of a single species were examined. The isolates obtained were identified using conventional methods. Antimicrobial susceptibilities of isolated organisms were determined using Kirby-Bauer disc diffusion system, with the recommendations of Clinical and Laboratory Standards Institute (CLSI) ${ }^{13}$.

Identification of the uropathogens: Uropathogens were isolated on Blood agar and MacConkey agar media. All the plates were incubated aerobically at
$35 \pm 2^{\circ} \mathrm{C}$ for $18-48$ hours and the colonies were studied. For confirmation of specific bacterial spp., standard biochemical tests (MIU, KIA, Citrate, Catalase, Coagulase, bile aesculin test) were performed.

Antimicrobial susceptibility testing: Antimicrobial susceptibility testing of the isolated bacterial spp. was performed by disc diffusion method following the CLSI guidelines ${ }^{13}$. Antibiotic discs used as follows: amikacin $(30 \mu \mathrm{g})$, amoxyclave $(30 \mu \mathrm{g})$, azithromycin $(15 \mu \mathrm{g})$, cefepime $(30 \mu \mathrm{g})$, cefixime $(05 \mu \mathrm{g})$, cefotaxime $(30 \mu \mathrm{g})$, ceftazidime $(30 \mu \mathrm{g})$, cefuroxime $(30 \mu \mathrm{g})$, ceftriaxone $(30 \mu \mathrm{g})$, cotrimoxazole $(25 \mu \mathrm{g})$, cloxacillin $(10 \mu \mathrm{g})$, cephradine $(30 \mu \mathrm{g})$, nalidixicacid $(30 \mu \mathrm{g})$, ciprofloxacin $(5 \mu \mathrm{g})$, imipenem $(10 \mu \mathrm{g})$, meropenem $(10 \mu \mathrm{g})$, nitrofurantoin $(300 \mu \mathrm{g})$ and gentamicin $(10 \mu \mathrm{g})$. This study was approved by local ethics committee.

\section{Results:}

A total of 2021 urine samples from patients of different age and sex of suspected UTI were included in this study. Of 2021 cases, 600 (29.68\%) were male and $1421(70.32 \%)$ were female. A total of 271(13.41 $\%)$ bacterial growths were isolated from 2021 urine samples. Rate of prevalence of uropathogens in male and female was $8.3 \%$ and $15.6 \%$ respectively, with a male to female ratio of 1:4.4 (Table 1).

Table1: Gender distribution and growth of uropathogens

\begin{tabular}{|l|l|l|l|}
\hline Sex & No of Sample & Growth & No growth \\
\hline Male & $600(29.68 \%)$ & $50(8.3 \%)$ & $550(91.7 \%)$ \\
\hline Female & $1421(70.32 \%)$ & $221(15.6 \%)$ & $1200(84.4 \%)$ \\
\hline Total & $2021(100 \%)$ & $271(13.4 \%)$ & 1750 \\
\hline
\end{tabular}

E. coli was the predominant isolates 180 (66.42\%), followed by Proteus spp. 31 (11.44\%), Klebsiella spp. 22 (8.12\%), Staphylococcus saprophyticus 13 (4.80\%), Pseudomonas spp.11 (4.06 \%), Enterococcus spp. 10 (3.69\%) and Staphylococcus aureus 04 (1.48\%), as shown in Table-2.

Table 2: Pattern of Bacterial Isolate from Urine Cultures

\begin{tabular}{|l|r|r|}
\hline \multicolumn{1}{|c|}{ ORGANISM } & Frequency & \multicolumn{1}{c|}{ Percent } \\
\hline E. coli & 180 & $66.42 \%$ \\
\hline Proteus & 31 & $11.44 \%$ \\
\hline Klebsiella & 22 & $8.12 \%$ \\
\hline Staph.saprophyticus & 13 & $4.80 \%$ \\
\hline Pseudomonas & 11 & $4.06 \%$ \\
\hline Enterococci & 10 & $3.69 \%$ \\
\hline Staph. Aureus & 4 & $1.48 \%$ \\
\hline Total & 271 & $100.00 \%$ \\
\hline
\end{tabular}


The antimicrobial resistance patterns of isolates are shown in Table 3. High frequency of resistance ranging from 30 to $82 \%$ to most of the drugs which included cefepime, amoxyclav, ciprofloxacin, ceftriaxone, cotrimoxazole, cefixime, ceftazidime, cefotaxime, azithromycin, nalidexic acid, and cefuroxime and low resistance which ranges from 9 to $1 \%$ included gentamycin $(9 \%)$, meropenem $(3 \%)$, imipenem $(2 \%)$, nitrofurantoin $(2 \%)$ and amikacin (1\%) were shown by E. coli.

Proteus showed high frequency of resistance to most of the drugs like cefixime, azithromycin, ceftazidime, cefuroxime, nalidexic acid ranges from $30 \%$ to $73 \%$, moderate resistance 16 to $29 \%$ to ciprofloxacin, cefepime, cefotaxime, ceftriaxone, amoxyclav, cotrimoxazole and low resistance to gentamycin (3\%) and amikacin (3\%). Meropenem and imipenem were found $100 \%$ sensitive.

Klebsiella showed high frequency of resistance to cefuroxime, ceftazidime, amoxyclav, cotrimoxazole, azithromycin, cefixime, cefotaxime, nalidexic acid, ceftriaxone, cefepime, ciporofloxacin ranges from
36 to $82 \%$. Nitrofurantoin, gentamycin, meropenem and amikacin showed low resistance from 9 to $24 \%$. Only imipenem was found $100 \%$ sensitive for this organism.

Staphylococcus saprophyticus was found resistant to few drugs, highest being to ceftazidime $85 \%$, cefepime $(58 \%)$, cefixime $(54 \%)$, nalidexic acid $(50 \%)$ and azithromycin (40\%). Cephradine, amikacin and imipenem were found $100 \%$ sensitive and rest of the drugs showed low resistance started from 8 to $25 \%$.

No drug for Pseudomonas found to be $100 \%$ effective. All the used drugs showed resistance started from 9\% (Imipenem) to $87 \%$ (Nitrofurantoin). Nalidexic acid, azithromycin, cotrimoxazole and cefotaxime were found $100 \%$ resistant to Enterococci and $83-80 \%$ for ciprofloxacin and cefepime. All other drugs were found resistant from 67 to $17 \%$. Some drugs are seen to be $100 \%$ sensitive to Staphylococcus aureus like nitrofurantoin, gentamycin, amikacin and imipenem. Again 100\% resistance was found for nalidexic acid.

Table 3: Antibiotic resistance pattern of uropathogens

\begin{tabular}{|l|c|c|c|c|c|c|c|}
\hline $\begin{array}{l}\text { Antimicrobial } \\
\text { agents }\end{array}$ & $\begin{array}{l}\text { E.coli } \\
\mathbf{N = 1 8 0}\end{array}$ & $\begin{array}{l}\text { Proteus } \\
\mathbf{N = 3 1}\end{array}$ & $\begin{array}{l}\text { Klebsiella } \\
\mathbf{N = 2 2}\end{array}$ & $\begin{array}{l}\text { S.Saprophyticus } \\
\mathbf{N}=\mathbf{1 3}\end{array}$ & $\begin{array}{l}\text { Pseudomonas } \\
\mathbf{N}=\mathbf{1 1}\end{array}$ & $\begin{array}{l}\text { Enterococci } \\
\mathbf{N = 1 0}\end{array}$ & $\begin{array}{l}\text { S. } \\
\text { aureus } \\
\mathbf{N = 4}\end{array}$ \\
\hline R* (\%) & $\mathrm{R}(\%)$ & $\mathrm{R}(\%)$ & $\mathrm{R}(\%)$ & $\mathrm{R}(\%)$ & $\mathrm{R}(\%)$ & $\mathrm{R}(\%)$ \\
\hline Amikacin & 01 & 03 & 09 & 00 & 10 & 17 & 00 \\
\hline Amoxyclav & 31 & 29 & 55 & 08 & 73 & 17 & 13 \\
\hline Cefepime & 30 & 17 & 36 & 58 & 55 & 80 & 50 \\
\hline Cefixime & 47 & 30 & 45 & 54 & 73 & 67 & 88 \\
\hline Cefotaxime & 52 & 23 & 44 & 12 & 45 & 100 & 20 \\
\hline Ceftazidime & 50 & 45 & 55 & 85 & 64 & 67 & 88 \\
\hline Cefuroxime & 82 & 62 & 82 & 25 & 82 & 50 & 75 \\
\hline Ceftriaxone & 41 & 26 & 41 & 08 & 36 & 50 & 25 \\
\hline Cephradine & - & - & - & 00 & - & 50 & 25 \\
\hline Ciporofloxacin & 38 & 16 & 36 & 08 & 18 & 83 & 25 \\
\hline Cloxacillin & - & - & - & 08 & - & 25 & 50 \\
\hline Cotrimoxazole & 43 & 29 & 48 & 31 & 50 & 100 & 25 \\
\hline Gentamicin & 09 & 03 & 18 & 08 & 27 & 17 & 00 \\
\hline Imipenem & 02 & 00 & 00 & 00 & 09 & 33 & 00 \\
\hline Meropenem & 03 & 00 & 16 & 18 & 27 & 50 & 12 \\
\hline Nalidexic acid & 74 & 73 & 43 & 50 & 82 & 100 & 100 \\
\hline Nitrofurantoin & 02 & - & 24 & 20 & 87 & 25 & 00 \\
\hline Azthromycin & 56 & 41 & 46 & 40 & 64 & 100 & 57 \\
\hline R-Resistanc| & & & & & & & \\
\hline
\end{tabular}

$* \mathrm{R}=$ Resistance 


\section{Discussion:}

Urinary tract infection is emerging as an important community acquired and nosocomial bacterial infection. Moreover, antimicrobial resistance to various classes of antimicrobials to uropathogens continues to be a major health problem in different parts of the world. ${ }^{14,15}$

Urinary tract infections (UTIs) are common in women, often associated with significant morbidity and mortality ${ }^{16}$ and may affect women of all age groups especially sexually active ones ${ }^{17}$.Our findings are also in agreement with this generalization and rightly coincided with a study done by Deshpande et al. ${ }^{18}$.

We studied 2021 urine samples and found significant growth in about $13.41 \%$ cases. The frequency is close to the incidence reported by Ahmed and Avasarala (2008), and Begum et al. (2006) 12.7\% and $16.4 \%$ respectively ${ }^{19,20}$. The findings of this study is higher than the study of Singh MM et al.(2001) ${ }^{21}$ who reported $4.2 \%$ UTI in a community based study but lower than the study of Bashar et al. (2009), and Ahmed et al. (2016) who reported frequency of UTI is $27 \%$ and $24.85 \%$ respectively in hospital or clinic based study ${ }^{22,23}$.

E. coli is the most common uropathogen (66.42\%) isolated from the cultured urine samples of this study population. This is similar to findings from studies done in other developing countries such as India $(68 \%)^{24}$ and Madagascar $(67 \%) .{ }^{25}$ Lower incidences from other studies observed like in India $59 \%{ }^{26}$ and $52.65 \%{ }^{27}$. Higher incidence found by Saber et al. $77.8 \%{ }^{28}$ and by Bosch et al. $75 \%$ in South Africa. ${ }^{29}$

According to a guideline published by Infectious Diseases Society of America (IDSA) in the year 2011, treatment of acute uncomplicated cystitis in women with nitrofurantoin, fosfomycin, trimethoprim-sulfamethoxazole, and pivmecillinam can be initiated, if regional resistance rates against aforesaid antibiotics does not exceed $20 \%$ and in cases of suspect acute pyelonephritis fluoroquinolones or beta-lactame antibiotics. ${ }^{9}$

In Bangladesh the antibiotic resistance uropathogens has now become a public health concern. ${ }^{30}$ If the patient doesn't maintain antibiotic dose regimen properly, the organism may emerge as drug resistant variant and eventually result in both nosocomial and community acquired UTIs. ${ }^{31,32}$ Increasing drug resistance is a great concern to common bacterial infections including UTI. For empirical use of antibiotic to treat uncomplicated UTI, many underdeveloped countries and developing countries like Bangladesh use antimicrobial agents like amoxicillin, cotrimoxazole, cephradine, nalidixic acid, ciprofloxacin, azithromycin. ${ }^{33}$ Unfortunately, it was found that all those agents had no acceptable range of sensitivity against $\mathrm{E}$ coli. This finding is alarming for an effective agent to find out for treatment against UTI and very difficult situation for physicians as well. Only gentamycin, meropenem, imipenem, nitrofurantoin and amikacin were found to have good sensitivity. But in uncomplicated UTI injectable drug are not acceptable because of compliance, so gentamycin is not a drug of choice. Meropenem, imipenem and amikacin are not use routinely and are kept as reserve for critical situation. So, nitrofurantoin was found to be reasonably effective agent among all antimicrobials against $E$. coli in the current setting and similar findings were seen in other studies..$^{34,35,36}$ Nitrofurantoin has some advantages too; it is cheap, can be taken orally. This study result clearly indicated that common drugs used against uncomplicated UTI are not effective for empirical treatment.

It needs to be considered whether the antimicrobial susceptibility profile of uropathogens identified in this study can be used as representative of the general situation in Bangladesh; if not, then more study to be done and real scenarios to be found out.

\section{Conclusion:}

Globally, the increasing rate of antibacterial resistance including our country is thought to be related to erroneous strategies of antibio-therapy. So it should be closely monitored both at the regional and national levels. As antibiotic resistance increasing, compared with previous years, there should be continued monitoring of this data to evaluate trend of resistance of antimicrobials for sustained optimization of empirical therapy.

\section{Conflict of interest: None declared.}




\section{References:}

1. Akram M, Shahid M, Khan AU. Etiology and antibiotic resistance patterns of community-acquired urinary tract infections in J N M C Hospital Aligarh, India. Ann Clin Microbiol Antimicrob. 2007; 6:4. https://doi.org/10.1186/1476-0711-6-4

2. Schaeffer AJ, Rajan N, Cao Q, Anderson BE, et al. Host pathogenesis in urinary tract infection. Int $J$ Antimicrob Agents. 2001; 7:245-51. https://doi.org/10.1016/S0924-8579(01)00302-8

3. Stamm WE. Urinary tract infections and pyeloephritis. In: Kasper DL, Braunwald E, Fausi AS, et al., editors. Harrison's principles of internal medicine. 16th ed. USA: McGraw-Hill companies Inc; 2005. p. 1715-21.

4. Guentzel MN. Escherichia, Klebsiella, Enterobacter, Serratia, Citrobacter, and Proteus. Barron's Medical Microbiology. 4th ed. Univ of Texas Medical Branch; 1996.

5. Arslan H. Komplikeolmayan, üriner system infeksiyonları: Rehberleryolgösterebiliyor mu? ANKEM Derg. 2012; 26:158-62.

6. Gupta S, Kapur S, Padmavathi DV. Comparative prevalence of antimicrobial resistance in communityacquired urinary tract infection cases from representative States of Northern and Southern India. J ClinDiagn Res. 2014;8:9-12.

7. Kashef N, EsmaeeliDjavid G, Shahbazi S. Antimicrobial susceptibility patterns of community-acquired uropathogens in Tehran, Iran. J Infect Dev Ctries. 2010;4:202-6. https://doi.org/10.3855/jidc.540

8. Gupta K, Sahm DF, Mayfield D, Stamm WE. Antimicrobial resistance among uropathogens that cause community-acquired urinary tract infections in women: a nationwide analysis. Clin Infect Dis. 2001;33(1):89-94. https://doi.org/10.1086/320880

9. Gupta K, Hooton TM, Naber KG, Wullt B, Colgan R, Miller LG. International clinical practice guidelines for the treatment of acute uncomplicated cystitis and pyelonephritis in women: A 2010 update by the Infectious Diseases Society of America and the European Society for Microbiology and Infectious Diseases. Clin Infect Dis. 2011;52:e103-20. https://doi.org/10.1093/cid/ciq257

10. Gold HS, Moellering RC. Antimicrobial drug resistance. $N$ Eng $J$ Med. 1996; 335:1445-53. https://doi.org/10.1056/NEJM199611073351907

11. Gupta K. Addressing antibiotic resistance. Am J Med. 2002; 113:295-345. https://doi.org/10.1016/S0002-9343(02)01057-4

12. Bauza E, Cercenado E. Klebsiellaand Enterobacterantibiotic resistance and treatment implications. SeminRespis Infect. 2002;17:215-30. https://doi.org/10.1053/srin.2002.34693

13. Clinical and Laboratory Standard Institute. Performance standards for antimicrobial susceptibility testing: sixteenth informational supplement 2006. CLSI document M100-S16 CLSI, Wayne, PA.

14. Oliveira FA, Paludo KS, Arend LNVS, Farah SMSS, Pedrosa FO, Souza EM, Surek M, Picheth G,
Fadel-Picheth CMT. Virulence characteristics and antimicrobial susceptibility of uropathogenicEscherichia coli strains. GenetMol Res. 2011;10:4114-25. https://doi.org/10.4238/2011.October.31.5

15. Farshad S, Ranjbar R, Japoni A, Hosseini M, Anvarinejad M, Mohammadzadegan, R. Microbial susceptibility, virulence factors and plasmid profiles of uropathogenicEscherichia coli strains isolated from children in Jahron. Iran. Arch Iran Med. 2012;15:3126.

16. Garner JS, Jarvis WR, Emori TG, Horan TC, Hughes JM. CDC definitions for nosocomial infections. Am J Infect Control. 1988; 16(3):128-140. https://doi.org/10.1016/0196-6553(88)90053-3

17. Foxman B, Zhang L, Tallman $\mathrm{P}$ etal. Transmission of uropathogens between sex partners. J Infect Dis. 1997; 175(4): 989-992. https://doi.org/10.1086/514007

18. Deshpande KD, Pichare AP, Suryawanshi NM, Davane MS. Antibiogram of gram negative uropathogens in hospitalized patients. Int J Recent Trends Sci Technol. 2011;1(2):56-60.

19. Ahmed SM, Avasarala AK. 2008. Urinary tract infections (UTI) among adolescent girls in rural Karimnagar district, AP - K.A.P. STUDY. Indian J PrevSoc Med.39, 1-2: 67-70.

20. Begum N, Mamoon ABA, Hossain M, Begum N, Chowdhury SA, Rahman MF. UTI among female workers in a selected garment industry of Dhaka city: A cross sectional study. TheORION Medical Journal. 2006; 23: 325-327.

21. Singh MM, Devi R, Garg S, Mehra M. Effectiveness of syndromic approach in management of reproductive tract infections in women. Indian J Med Sci. 2001; 55(4): 209-214.

22. Bashar MA, Ahmed MF, Rahman SR, Gomes DJ. Distribution and Resistance Trends of Escherichia coli from Urinary Tract Infections Isolated in Dhaka City. Ban J Med Sci. 2009; 15(2): 93-98.

23. Ahmed A A, Alam A N, Fatmi R, Rahman MM, Munia MS, Juyee N A.2016. Antibiotic Sensitivity pattern of uropathogens at KhwajaYunus Ali Medical College Hospital. Journal of KhwajaYunus Ali Medical College. 2016; 6(2):610-13.

24. Kothari A, Sagar V. Antibiotic resistance in pathogens causing community acquired urinary tract infections in India: A multicenter study. $J$ Infect DevCtries. 2008; 2(5):354-358.

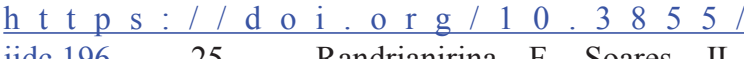
jidc.196 25. Randrianirina F, Soares JL, Carod JF, et al. Antimicrobial resistance among uropathogens that cause community-acquired urinary tract infections in Antananarivo, Madagascar. J AntimicrobChemother. 2007; 59(2):309-312. https://doi.org/10.1093/jac/dkl466

26. DH, Dhanorkar DV, Gulhane SR, et al. Antibacterial susceptibility of some urinary tract pathogens to commonly used antibiotics. Afr J Biotechnol. 2006; 5(17):1562-1565.

27. Jan N, Meshram SU \&Kulkarni A. Plasmid profile 
Antibiotic resistance pattern of bacteria causing urinary tract infection in a private medical college hospital, Dhaka

analysis of multidrug resistant E. coli isolated from UTI patients of Nagpur City, India. Romanian Biotechnological Letters. 2009; 14(5): 4635-4640.

28. Saber MH, Barai L, J Haq A, Jilani MSA \& Begum MJ. The Pattern of Organism Causing Urinary Tract Infection in Diabetic and Non Diabetic Patients in Bangladesh. Bangladesh JMed Microbiol. 2010; 04(01): 6-8.

29. Bosch FJ, van Vuuren C, Joubert G. Antimicrobial resistance patterns in outpatient urinary tract infections - the constant need to revise prescribing habits. $S$ Afr Med J. 2011; 101(5):328-331. PMid:21837876 https://doi.org/10.7196/SAMJ.4346

30. Rahman MM, Haq JA, Hossain MA, Sultana R, Islam F, Islam AH. Prevalence of extended-spectrum beta-lactamase-producing Escherichia coli and Klebsiellapneumoniae in an urban hospital in Dhaka, Bangladesh.IntJAntimicrobAgents.2004;24(5):508-510. https://doi.org/10.1016/j.ijantimicag.2004.05.007

31. Gales AC, Gordon KA, Wilke WW, Pfaller MA, Jones RN. Occurrence of single-point gyrA mutations among ciprofloxacinsusceptibleEscherichia coli isolates causing urinary tract infections in Latin America.
Diagn Microbiol Infect Dis .2000; 36(1): 61-64. https://doi.org/10.1016/S0732-8893(99)00121-2

32. Gupta K, Stamm WE. Pathogenesis and management of recurrent urinary tractinfections in women. World J Urol. 1999; 17(6): 415-420. https://doi.org/10.1007/s003450050168

33. RezwanaHaque, Most. LailaAkter and Md. Abdus Salam. Prevalence and susceptibility of uropathogens: a recent report from a teaching hospital in Bangladesh. BMC Res Notes (2015); 8:416(1-5)

34. Sharifian M, Karimi A, Rafiee-Tabatabaei S, et al. Microbial sensitivity pattern in urinary tract infections in children: a single center experience of 1177 urine cultures. Jpn J Infect Dis. 2006; 59:380-2.

35. Kothari A, Sagar V. Antibiotic resistance in pathogens causing community-acquired urinary tract infections in India: a multicenter study. $J$ Infect DevCtries. 2008; 2:354-8. https://doi.org/10.3855/jidc.196

36. Sohely S, Farhana AF, Fahmida, Saleh AA. Sensitivity pattern of uropathogens in children. Bangladesh J Med Microbiol. 2009; 3(1):18-22. 